\title{
PNE 2014-2024 e a redução das desigualdades regionais: entre a proposição e a realidade
}

\author{
PNE 2014-2024 and the reduction of the regional inequalities: \\ between the proposal and the reality
}

PNE 2014-2024 et la réduction des inégalités régionales: entre proposition et réalité

Suely Ferreira - UFG ${ }^{1}$ Universidade Federal de Goiás

Karine Nunes de Moraes - UFG ${ }^{2}$ Universidade Federal de Goiás

João Ferreira de Oliveira - UFG ${ }^{3}$ Universidade Federal de Goiás

Resumo: O artigo tem como objetivo analisar a meta 12 do PNE (2014-2024), particularmente os indicadores da taxa líquida e bruta de matrícula da educação superior e problematizar as assimetrias inter e intrarregional de seu acesso. A pesquisa é do tipo exploratório e documental, considerando os dados levantados no âmbito do Projeto Integrado de Pesquisa "Expansão e qualidade da educação superior no contex to do Plano Nacional de Educação (2014-2024): Tensões, limites e perspectivas", financiado pelo CNPq. O estudo evidencia a necessidade de um grande esforço nacional para alcançar a meta 12 e que esse esforço precisa ser ainda maior nas regiões Norte e Nordeste.

Palavras-chave: Plano Nacional de Educação. Educação Superior. Acesso ao Ensino Superior. Desigualdade Regional. Direito à Educação Superior.

Abstract: The article aims to analyze the goal 12 of the PNE (2014-2024), particularly the indicators of the net rate and the gross rate of enrollment in higher education, and to problematize the inter and intraregional asymmetries of its access. The research is exploratory and documentary, considering the data collected within the scope of the Integrated Research Project "Expansion and quality of higher education in the context of the National Education Plan (2014-2024): Tensions, limits and perspectives", funded by CNPq. The study shows that a great national effort is needed to reach the goal 12 and that this effort needs to be even greater in the North and Northeast regions.

Keywords: National Plan for Education. Higher education. Access to Higher Education. Regional Inequality. Right to Higher Education.

\footnotetext{
${ }^{1}$ Doutora em Educação pela Universidade Federal de Goiás. Professora da Universidade Federal de Goiás. E-mail: suelyferreira13@gmail.com._ Lattes:_ http://lattes.cnpq.br/3692445113505114. ORCID: http://orcid.org/0000.0001-8990-8493.

${ }^{2}$ Doutora em Educação pela Universidade Federal de Pernambuco. Professora da Universidade Federal de Goiás. E-mail: karine_ufg@ufg.br. Lattes: http://lattes.cnpq.br/6017907286532794. ORCID: https://orcid.org/o000-0003-0812-1694 ${ }^{3}$ Doutor em Educação pela Universidade de São Paulo. Professor da Universidade Federal de Goiás. Email: joao.jferreira@gmail.com. Lattes: http://lattes.cnpq.br/9753142663168623. ORCID: https://orcid.org/0000-0002-4135-6340.
} 
Résumé: Cet article vise à analyser l'objectif numéro 12 du PNE (2014-2024), en particulier les indicateurs du taux net et brut de scolarisation de l'enseignement supérieur, et à problématiser les asymétries inter et intra-régionales de son accès. La recherche est exploratoire et documentaire, considérant les données collectées dans le cadre du Projet de Recherche Intégrée "Expansion et qualité de l'enseignement supérieur dans le cadre du Plan National d'Education (2014-2024): tensions, limites et perspectives", financé par le CNPq . L'étude montre qu'un grand effort national est nécessaire pour atteindre l'objectif numéro 12 et que cet effort doit être encore plus important dans les régions du nord et du nord-est du Brésil.

Mots-clés: Plan National d'Éducation. Éducation universitaire. Accès à l'enseignement supérieur. Inégalité régionale. Droit à l'enseignement supérieur.

Enviado em: 24 de maio de 2020 Aceito em: 08 de outubro de 2020

\section{Introdução}

O censo da educação superior no Brasil tem evidenciado grande desigualdade no acesso a esse nível, assim como a manutenção de assimetrias inter e intrarregionais. Decorrido o tempo de implementação do PNE (2001-2010) e da metade do tempo para o Plano atual (2014-2024), a não garantia do direito à educação ainda está presente, em intensidade diferente, em todas as regiões do país. Acrescenta-se o fato de o país ter ficado quatro anos sem a cobertura, mesmo que formal, do PNE em descumprimento à Constituição Federal de 1988, artigo 214, que determina a necessidade da existência do PNE de duração plurianual com diretrizes, objetivos, metas e estratégias.

É objetivo deste artigo analisar a meta 12 do PNE (2014-2024) em vigência, particularmente no que se refere aos indicadores da taxa líquida de matrícula (TLM) e da taxa bruta de matrícula (TBM), bem como as assimetrias regionais e intrarregionais que explicitam as desigualdades em relação ao acesso à educação superior e aos desafios para superá-las. Vale ressaltar que o PNE (2001-2010) tinha como meta alcançar 30\% da TLM e alcançou apenas 17,3\%. Já o PNE (2014-2024) retomou a meta, reajustando para os tímidos $33 \%$ até o final do novo decênio estabelecido.

Este estudo ocorre no âmbito do Projeto Integrado de Pesquisa "Expansão e qualidade da educação superior no contexto do Plano Nacional de Educação (2014-2024): tensões, limites e perspectivas", que visa analisar as políticas, os indicadores, as metas, as estratégias e os processos de expansão da educação superior, estabelecidas, sobretudo, a partir do PNE (2014-2024), considerando-se as tensões, os limites e as perspectivas de 
Revista Educação e Políticas em Debate - v. 10, n. 1, p. 379-396, jan./abr. 2021 - ISSN 2238-8346 qualidade acadêmica, bem como a compreensão do papel da educação superior no projeto de desenvolvimento econômico e social do país.

\section{Desigualdades educacionais regionais no âmbito da Educação Superior}

O PNE (2014-2024) estabelece como meta para a expansão da educação superior a elevação da taxa bruta de matrícula para $50 \%$ e a taxa de matrícula líquida para $33 \%$ da população de 18 a 24 anos, e, também, que pelo menos $40 \%$ das novas matrículas sejam no segmento público, assegurada a qualidade da oferta e da expansão (Meta 12). Se essa meta em si representa um desafio decenal, considerando-se o cenário brasileiro, ele é ainda maior quando considerados os dados regionais e intrarregionais.

A TBM representa a razão entre o quantitativo de pessoas de qualquer idade que está matriculada em cursos de educação superior e o total geral de pessoas entre 18 e 24 anos de idade, que é a referência para frequentar esse nível de ensino. Já a TLM representa a proporção da população de 18 a 24 anos de idade matriculada nos cursos de educação superior. Nessa análise comparativa, consideraremos o total de pessoas na faixa etária de 18 a 24 anos, o número total de matrículas na educação superior, o número de matriculados na faixa etária de 18 a 24 anos nesse nível de educação e o número de instituições de ensino superior (IES).

O país possui um total de 2.407 IES, dessas, 46,8\% se concentram na região Sudeste, $19,9 \%$ na região Nordeste e 16,8\% na região Sul. Essas regiões também concentram o maior percentual da população na faixa etária de 18 a 24 anos, sendo 40\%, 28\% e 13,5\%, respectivamente. Já a região Centro-Oeste responde por 10\% das IES e 7,8\% da população de 18 a 24 anos e a região Norte responde por $6,5 \%$ e 9,8\%, respectivamente (Tabela 1).

Tabela 1 - População na faixa de 18 a 24 anos e número de IES no Brasil por regiões - 2016.

\begin{tabular}{|l|c|c|c|c|}
\hline \multicolumn{1}{|c|}{ Regiões } & $\begin{array}{c}\text { Número de } \\
\text { IES }\end{array}$ & \% & $\begin{array}{c}\text { População } \\
\mathbf{1 8} \text { a 24 anos }\end{array}$ & \% \\
\hline Norte & 156 & 6,5 & 2.211 .148 & 9,8 \\
\hline Nordeste & 480 & 19,9 & 6.505 .426 & 28,9 \\
\hline Sudeste & 1126 & 46,8 & 9.024 .735 & 40,0 \\
\hline Sul & 405 & 16,8 & 3.032 .541 & 13,5 \\
\hline Centro-Oeste & 240 & 10 & 1.764 .411 & 7,8 \\
\hline Brasil & 2407 & 100,0 & 22.538 .261 & 100 \\
\hline
\end{tabular}

Fonte: Censo da Educação superior 2012-2016, Pnad/IBGE 2012-2015 e Pnac/4 trim. Dados levantados no âmbito do Projeto Integrado de Pesquisa "Expansão e qualidade da educação superior no contexto do Plano Nacional de Educação (2014-2024): Tensões, limites e perspectivas”, UFG/UFRN, financiado pelo CNPq.

O aparente equilíbrio entre o percentual de IES e de pessoas entre 18 e 24 anos entre as regiões brasileiras esconde diferenças significativas no percentual de matrículas e de assimetrias 
Revista Educação e Políticas em Debate - v. 10, n. 1, p. 379-396, jan./abr. 2021 - ISSN 2238-8346 que indicam os desafios para o atendimento da meta 12 do PNE. O esforço para alcançar $50 \%$ da TBM será diferente de região para região e, mais ainda, para alcançar 33\% da TLM, apesar do significativo crescimento apresentado no período de 2012 a 2017, conforme Tabela 2.

Tabela 2 - Percentual da taxa bruta de matrícula e taxa líquida de matrículas por região - 2012 e 2017.

\begin{tabular}{|l|c|c|c|c|c|c|}
\hline País/Regiões & $\begin{array}{c}\text { TBM } \\
\text { 2012 }\end{array}$ & $\begin{array}{c}\text { TBM } \\
2017\end{array}$ & $\begin{array}{c}\text { Diferença } \\
2012-2017\end{array}$ & $\begin{array}{c}\text { TLM } \\
2012\end{array}$ & $\begin{array}{c}\text { TLM } \\
2017\end{array}$ & $\begin{array}{c}\text { Diferença } \\
2012-2017\end{array}$ \\
\hline Brasil & $30,88 \%$ & $36,11 \%$ & $5,23 \%$ & $15,62 \%$ & $18,58 \%$ & $2,96 \%$ \\
\hline Norte & $25,59 \%$ & $29,82 \%$ & $4,23 \%$ & $10,54 \%$ & $13,99 \%$ & $3,45 \%$ \\
\hline Nordeste & $21,73 \%$ & $26,83 \%$ & $5,10 \%$ & $10,44 \%$ & $13,48 \%$ & $3,04 \%$ \\
\hline Sudeste & $35,58 \%$ & $39,93 \%$ & $4,35 \%$ & $18,38 \%$ & $20,70 \%$ & $2,32 \%$ \\
\hline Sul & $36,10 \%$ & $44,47 \%$ & $8,37 \%$ & $19,54 \%$ & $23,68 \%$ & $4,14 \%$ \\
\hline Centro-Oeste & $37,93 \%$ & $43,42 \%$ & $5,49 \%$ & $19,80 \%$ & $23,11 \%$ & $3,31 \%$ \\
\hline
\end{tabular}

Fonte: Censo da Educação superior 2012-2016, Pnad/IBGE 2012-2015 e Pnac/4 trim. Dados levantados no âmbito do Projeto Integrado de Pesquisa "Expansão e qualidade da educação superior no contexto do Plano Nacional de Educação (2014-2024): Tensões, limites e perspectivas",

$\mathrm{UFG} / \mathrm{UFRN}$, financiado pelo CNPq.

Os dados gerais mostram que o Brasil tem uma TBM de 36,11\%, com um crescimento de 5,23\% no período de 2012 a 2017. Nesse mesmo período, as regiões Sul, Centro-Oeste e Sudeste apresentaram índices de TBM superiores ao nacional, registrando 44,47\%, 43,42\% e $39,93 \%$, respectivamente. Quando observado a diferença entre a taxa de TBM nesse período, destacam-se a região Sul com 8,37\% e a região Centro-Oeste, com 5,49\%. A região Nordeste, apesar de apresentar as taxas inferiores ao nacional e às demais regiões, seguido pela região Norte, registrou aumento da matrícula maior do que na região Sudeste. Apesar dos avanços constatados em 2017 em relação ao ano de 2012, persistem as graves assimetrias em relação às regiões Norte e Nordeste. Os dados indicam como as regiões Norte e Nordeste encontramse mais distantes para cumprir a meta de 50\% para TBM.

De modo semelhante, as regiões Sul, Centro-Oeste e Sudeste apresentam os melhores índices de TLM, superior ao nacional, sendo $23,68 \%, 23,11 \%$ e 20,70\% respectivamente. Nesse quesito, a região Norte responde por 13,99\% e a Nordeste por 13,48\%, sendo inferior às demais regiões. Quando observado o crescimento nos índices de TLM, a região Sul apresenta o melhor índice, com 4,14\%, destacando as regiões Norte e Nordeste com índices 3,45\% e 3,04\%, superiores à média nacional no mesmo período, mas ainda longe de alcançar a meta de 33\% da TLM (Tabela 2).

A assimetria entre as regiões brasileiras no que se refere às taxas de matrícula bruta e líquida também se reproduz e se amplia na dimensão intrarregional, indicando a necessidade de maior esforço por estados dentro de uma mesma região, em que pesem os avanços constatados em 2017 em relação ao ano de 2012. 
Revista Educação e Políticas em Debate - v. 10, n. 1, p. 379-396, jan./abr. 2021 - ISSN 2238-8346

Conforme indicado na tabela 2, a região Nordeste apresenta índices de TBM e TLM inferiores à média nacional e entre as demais regiões. Quando observado como isso se manifesta intrarregionalmente, o estado no Maranhão registra 20,99\% de TBM e o Piauí 34\%, apresentando uma TLM de 9,98\% e 18,86\%, respectivamente, indicando uma diferença de 13,01\% na TBM e de 8,88\% na TLM. Na região Norte, com índices de matrícula também abaixo da média nacional, destacam-se na TBM os estados do Pará com 23,60\% e Roraima com 42,23\%, uma diferença de 18,63\%. Na TLM, os estados do Pará com 10,64\% e Tocantins com $21,88 \%$, uma diferença de $11,24 \%$. Nas regiões com índices superiores às taxas nacionais, as diferenças intrarregionais também expressam, com maior destaque, as diferenças registradas na região Centro-Oeste. Com uma TBM de 43,42\%, o estado de Goiás registra taxa de 32,70\%, inferior à média nacional (36,11\%), e o Distrito Federal, uma taxa de 61,47\%, uma diferença de $28,77 \%$. Os mesmos estados apresentam as maiores assimetrias na TLM, sendo 18,88\% em Goiás e 32,66\% no Distrito Federal, uma diferença de 13,78\%. A região sudeste também registra taxas superiores e inferiores às nacionais entre seus estados. No que se refere a TBM, o estado de Minas Gerais registra 35,08\%, e o de São Paulo 42,14\%. E na TLM, as maiores diferenças estão entre os estados de Espírito Santos e de São Paulo, com taxas de $18,72 \%$ e 22,15, respectivamente. Esses dados indicam que, além do esforço nacional para o alcance dos indicadores da meta 12, a intensidade desse esforço deve se dar de modo diferente, considerando-se as regiões brasileiras e, mais ainda, os dados intrarregionais.

Dimensionando as significativas desigualdades em relação à TLM entre os entes federados, as taxas mais altas registram-se no Distrito Federal (32,66\%) e na Região Sul do país, sendo Santa Catarina (24,86\%), Paraná (23,30\%) e Rio Grande do Sul (23,27\%). Já as taxas mais baixas concentram-se nas regiões Norte e Nordeste, sendo Pará (10,64\%), Alagoas (12,63\%), Bahia (11,49\%) e Maranhão (9,98\%). A partir desses dados, constata-se que o Distrito Federal praticamente já atingiu a meta prevista para 2024, enquanto outros estados dificilmente poderão lograr êxito, caso não sejam implementadas políticas que tratem das especificidades de cada um para reverter esse quadro.

Vale dizer que os estados podem apresentar fenômenos como a queda ou o baixo crescimento da população na faixa etária de 18 a 24 anos; o aumento ou diminuição das populações que frequentam a educação superior; o aumento ou a diminuição da oferta de cursos, de vagas, dentre outros. Esses fatores podem impactar nas taxas líquida e bruta de matrículas no decorrer dos períodos. Portanto, combater as desigualdades passa por compreender as especificidades das localidades, não somente demográficas, mas também socioeconômicas e empreender políticas dirigidas ao atendimento das particularidades regionais. 
Revista Educação e Políticas em Debate - v. 10, n. 1, p. 379-396, jan./abr. 2021 - ISSN 2238-8346

Outro aspecto importante refere-se à quantidade de IES por região e a população na faixa etária de 18 a 24 anos, assim como as possíveis dificuldades de acesso. Dessa forma, para além do quantitativo de IES, outras especificidades importantes de oferta devem ser também analisadas, como o número de instituições que estão presentes com maior quantidade de vagas e matrículas nessas regiões, bem como os formatos de organização institucional, a forma de oferta e as diferentes modalidades terminais.

\section{Expansão da Educação Superior e assimetrias inter e intrarregionais no número de matrículas}

O alcance das metas do PNE (2014-2024) voltadas para a expansão da educação superior, no corte etário de 18 a 24 anos, está diretamente relacionado ao cumprimento das metas da educação básica, particularmente do ensino médio. Também se relaciona com o fortalecimento do regime de colaboração entre a União e os entes federados (estados, municípios e Distrito Federal), com a diminuição das desigualdades regionais e intrarregionais, na medida em que as IES municipais e estaduais possuem um importante papel na oferta de matrículas na educação superior e com o processo de interiorização desse nível de educação.

O PNE aprovado para o decênio 2001-2010 estabeleceu 34 metas para a educação superior sem, todavia, a indicação de estratégias por meta. Apontava para uma baixa taxa líquida de matrícula da população entre 18 e 24 anos (13,1\%), prevendo sua elevação para 30\%; e baixa taxa bruta de matrícula (24,3\%), assim como a oferta bastante desigual de oportunidades educacionais do ponto de vista regional. Aquém da média nacional, a região Nordeste apresentava os índices mais baixos, sendo 15,9\% de TBM e 7,7 de TLM, seguido pela região Norte com 19,3\% e 9,0\%. Acima da média nacional, a região Sul com 30,8\% e 16,8\%, região Sudeste com 28,6\% e 16,4\% e região Centro-Oeste com 28,8 e 15,6\%, respectivamente (Tabela 3).

Tabela 3 - Percentual da taxa bruta de matrícula e taxa líquida de matrículas por região - 2007 e 2017.

\begin{tabular}{|l|c|c|c|c|c|c|}
\hline País/Regiões & $\begin{array}{c}\text { TBM } \\
2007\end{array}$ & $\begin{array}{c}\text { TBM } \\
2017\end{array}$ & $\begin{array}{c}\text { Diferença } \\
2007-2017\end{array}$ & $\begin{array}{c}\text { TLM } \\
2007\end{array}$ & $\begin{array}{c}\text { TLM } \\
2017\end{array}$ & $\begin{array}{c}\text { Diferença } \\
\text { 2007-2017 }\end{array}$ \\
\hline Brasil & $24,3 \%$ & $36,11 \%$ & $11,81 \%$ & $13,1 \%$ & $18,58 \%$ & $5,48 \%$ \\
\hline Norte & $19,3 \%$ & $29,82 \%$ & $10,52 \%$ & $9,0 \%$ & $13,99 \%$ & $4,99 \%$ \\
\hline Nordeste & $15,9 \%$ & $26,83 \%$ & $10,93 \%$ & $7,7 \%$ & $13,48 \%$ & $5,78 \%$ \\
\hline Sudeste & $28,6 \%$ & $39,93 \%$ & $11,33 \%$ & $16,4 \%$ & $20,70 \%$ & $4,3 \%$ \\
\hline Sul & $30,8 \%$ & $44,47 \%$ & $13,67 \%$ & $16,8 \%$ & $23,68 \%$ & $6,88 \%$ \\
\hline Centro-Oeste & $28,8 \%$ & $43,42 \%$ & $14,62 \%$ & $15,6 \%$ & $23,11 \%$ & 7,51 \\
\hline
\end{tabular}

Fonte: Censo da Educação Superior. Inep, 2007 e 2017. Elaboração própria. 
Revista Educação e Políticas em Debate - v. 10, n. 1, p. 379-396, jan./abr. 2021 - ISSN 2238-8346

Em que pese as diferenças regionais, no que se refere às taxas de matrícula na educação superior, a meta voltada para o estabelecimento de uma política de expansão para a redução das desigualdades de oferta existente entre as diferentes regiões do país e a ampliação da oferta de ensino público, de modo a assegurar uma proporção nunca inferior a $40 \%$ do total de vagas, prevendo inclusive a parceria da União com os estados na criação de novos estabelecimentos de educação superior, foram vetadas na aprovação do PNE (20012010) pelo presidente Fernando Henrique Cardoso. Assim como as metas que definiam a criação do Fundo de Manutenção e de Desenvolvimento da Educação Superior e a aplicação de, pelo menos, $75 \%$ dos recursos da União vinculados à manutenção e ao desenvolvimento do ensino, destinados à manutenção e à expansão da rede de instituições federais e o investimento de $7 \%$ do Produto Interno Bruto (PIB) em educação.

Os vetos presenciais ao PNE (2001-2010), a falta de definição de estratégias para a implementação e o acompanhamento de sua implementação, sua secundarização na elaboração de políticas, de programas e de ações criaram significativos obstáculos para o cumprimento das metas tanto para a educação básica como para a educação superior. Contudo, apesar de a expansão da educação superior se concentrar sobretudo na esfera privada, cabe destacar a significativa expansão da rede federal a partir de 2003 com a implementação de um conjunto de políticas, de programas e de ações, sob o discurso de democratização da educação superior pública, gratuita e de qualidade, que impactaram a elaboração, a aprovação e a implementação do PNE (2014-2024), dentre eles:

1) o Programa de Expansão das Instituições Federais de Educação Superior (Ifes) com vistas a ampliar o acesso à educação superior, a promover a inclusão social, a reduzir as desigualdades regionais por meio da interiorização e da desconcentração da oferta de cursos e de vagas nesse nível de ensino, além de contribuir com o desenvolvimento local e regional, reduzindo as assimetrias intra e entre regiões, por meio da implantação de dez novas universidades federais e da criação ou da consolidação de 49 campi nas cinco regiões brasileiras.

2) o Processo de Integração de Instituições Federais de Educação Tecnológica, para constituição dos Institutos Federais de Educação, Ciência e Tecnologia (IF), no âmbito da Rede Federal de Educação Tecnológica - essas instituições deveriam concentrar-se na oferta especializada de educação profissional e tecnológica nas diferentes modalidades e níveis educacionais, incluindo programas de pós-graduação lato e stricto sensu, cujas ações passassem pela formação e qualificação de profissionais para os diversos setores da economia, em articulação com os setores produtivos e a sociedade, estimulando a geração e a adaptação de 
Revista Educação e Políticas em Debate - v. 10, n. 1, p. 379-396, jan./abr. 2021 - ISSN 2238-8346 soluções técnicas e tecnológicas às demandas sociais e peculiaridades regionais, atuando para a redução das desigualdades regionais.

3) o Programa de Apoio a Planos de Reestruturação e Expansão das Universidades Federais (Reuni) - objetivando criar condições para a ampliação do acesso e da permanência na educação superior no nível de graduação por meio do aumento do número de matrículas, redução das taxas de evasão, ocupação de vagas ociosas, aumento da oferta de vagas de ingresso, especialmente no período noturno, melhoria da estrutura física e do quadro de docentes e técnico-administrativos existentes nas universidades federais.

4) o Sistema Universidade Aberta do Brasil (UAB) - criado pelo Ministério da Educação (MEC), no âmbito do Fórum das Estatais pela Educação e da Associação Nacional dos Dirigentes das Instituições Federais de Ensino Superior (Andifes), para articulação e integração de um sistema nacional de educação superior a distância, visando sistematizar ações, programas e projetos, atividades que envolvem políticas públicas voltadas para expansão e interiorização da oferta de ensino superior gratuito e de qualidade no Brasil.

Também destacam-se no conjunto das medidas adotadas para expansão da educação superior e ampliação do acesso com permanência: 1) a Portaria ${ }^{\circ}$ 3.284/2003, que define as condições referenciais de acessibilidade à educação superior que devem ser construídas nas IES para instruir o processo de avaliação dessas instituições; 2) a norma ABNT NBR n ${ }^{\circ}$ 9.050/04, que dispõe sobre a acessibilidade arquitetônica a edificações, mobiliário, espaços e equipamentos urbanos; 3) o Decreto $\mathrm{n}^{\circ}$ 5.296/04, que regulamenta as Leis $\mathrm{n}^{\circ}$ 10.048/2000 e $\mathrm{n}^{\circ}$ 10.098/2000, estabelecendo normas gerais e critérios básicos para o atendimento prioritário à acessibilidade de pessoas com deficiência ou com mobilidade reduzida; 4) o Decreto no 5.626/2005, que regulamenta a Lei ${ }^{\circ}$ 10.436/2002, que dispõe sobre uso e difusão da Língua Brasileira de Sinais - LIBRAS e estabelece que os sistemas educacionais devem garantir, obrigatoriamente, o ensino de LIBRAS em todos os cursos de formação de professores e de fonoaudiologia e, optativamente, nos demais cursos de educação superior; 5) o Programa Acessibilidade Ensino Superior (Incluir/2005), que determina a estruturação de núcleos de acessibilidade nas instituições federais de educação superior que visam eliminar barreiras físicas, de comunicação e de informação que restringem a participação e o desenvolvimento acadêmico e social de estudantes com deficiência; 6) a Política Nacional de Educação Especial na Perspectiva da Educação Inclusiva (BRASIL, 2008); 7) o Decreto $\mathrm{n}^{\circ}$ 6.949/2009, que assegura o acesso aos referenciais de acessibilidade na educação superior, segundo a constituição de um sistema educacional inclusivo em todos os níveis; 8) o Decreto no 7.611/2011, que dispõe sobre o atendimento educacional especializado, que prevê, no Art. $5^{\circ}, \S 2^{\circ}$, a estruturação de 
Revista Educação e Políticas em Debate - v. 10, n. 1, p. 379-396, jan./abr. 2021 - ISSN 2238-8346 núcleos de acessibilidade nas instituições federais de educação superior; 9) a Lei $n^{\circ}$ 13409/2016, que altera a Lei no $12711 / 2012$, que estabelece reserva de vagas para alunos com deficiência nos cursos de nível médio e superior nas instituições federais de ensino, por curso e por turno, com proporção de vagas equivalente à porcentagem de pessoas com deficiência na unidade federativa. (BRASIL, 2008; 2013a; 2013b, 2015, 2016).

Com isso, mesmo ficando praticamente inalterada a proporção de matrículas entre as esferas pública e privada, registra-se o crescimento considerável das matrículas na rede federal nos cursos de graduação presencial que passou de 567.101, em 2003, para 1.175.650, em 2016, um crescimento de 107,30\% (BRASIL, 2003-2016). Impacto, também, no que se refere à ampliação do atendimento da população entre 18 e 24 anos. A TLM passou de 10,6\% em 2003 para $18,31 \%$, em 2016. Já a taxa bruta de matrícula passou de $18,6 \%$ para $35,71 \%$. Quando comparamos a evolução da taxa de escolarização bruta e líquida entre as regiões brasileiras, verifica-se o crescimento expressivo em todas as regiões, com destaque para a região CentroOeste, que passou de $23,6 \%$ para $42,60 \%$ e de $12,3 \%$ para 22,64\%, respectivamente (IBGE/PNAD e PnadC 2016/4ำ Trim; BRASIL, 2003-2016).

A interiorização da rede federal também se destacou no período de 2003 a 2016, como resultante das políticas de expansão da educação superior (Tabela 4). O número de IES em 2003, que era de 83, sendo 52 na capital e 31 no interior, aumentou para 107 em 2016, sendo 64 na capital e 43 no interior, destacando o crescimento de $38,71 \%$ no número de IES no interior. O número de cursos passa de 2.393 para 5.938 (148,14\%), sendo que na capital passou de 1.243 para 2.311 (85,92\%) e no interior passou de 1.149 para 3.627 (215,67\%). O número de matrículas passa de 567.101 para 1.175 .650 (107,31\%), sendo que capital passou de 376.818 para $568.794(50,95 \%)$ e no interior passou de 190.283 para $606.856(218,92 \%)$.

Tabela 4 - Número de instituições de ensino superior, curso e matrícula, por capital e interior - 2003 e 2016.

\begin{tabular}{|l|c|c|c|c|c|c|}
\hline \multirow{2}{*}{ CATEGORIA } & \multicolumn{2}{|c|}{ TOTAL } & \multicolumn{2}{c|}{ CAPITAL } & \multicolumn{2}{c|}{ INTERIOR } \\
\cline { 2 - 7 } & $\mathbf{2 0 0 3}$ & $\mathbf{2 0 1 6}$ & $\mathbf{2 0 0 3}$ & $\mathbf{2 0 1 6}$ & $\mathbf{2 0 0 3}$ & $\mathbf{2 0 1 6}$ \\
\hline IES & 83 & 107 & 52 & 64 & 31 & 43 \\
\hline Curso & 2.392 & 5.938 & 1.243 & 2.311 & 1.149 & 3.627 \\
\hline Matrícula & 567.101 & 1.175 .650 & 376.818 & 568.794 & 190.283 & 606.856 \\
\hline
\end{tabular}

Fonte: Censo da Educação Superior. Inep, 2003 e 2016.

Outro aspecto a ser destacado é o crescimento do número da matrícula no período noturno, que passou de 144.391, em 2003, para 353.912 em 2016, registrando um crescimento de 145,11\%. 
Revista Educação e Políticas em Debate - v. 10, n. 1, p. 379-396, jan./abr. 2021 - ISSN 2238-8346

\section{O PNE (2014-2024): novas possibilidades de expansão da Educação Superior}

O acompanhamento do processo de expansão da educação superior, meta 12 do PNE (2014-2024), tem indicado a implementação de estratégias relacionadas, em parte, a programas e a ações pré-existentes tais como: Programa Reuni, UAB, Programa Nacional de Formação de Professores da Educação Básica (Parfor), a políticas de cotas e políticas de ações afirmativas, expansão do financiamento estudantil (Fies) e Programa Universidade para Todos (ProUni). Paradoxalmente, à medida que o processo de privatização da oferta da educação superior, que já estava em curso desde os anos 1990, se consolida, registra-se a significativa expansão do setor público, em especial da rede federal, como demostrado anteriormente.

Em que pese a aprovação do PNE (2014-2024) sem vetos pelo governo federal, com a meta de aplicar $10 \%$ do PIB na educação até o fim do decênio (Meta 20), a partir do impeachment da presidenta Dilma Rousseff e, em especial, com a aprovação da Emenda Constitucional n ${ }^{\circ}$. 95, de 15 de Dezembro de 2016, no governo Temer (2016-2018) e com as atuais sinalizações do governo Bolsonaro (2019-2022), evidenciou-se que o Plano não se constituiu como epicentro da política de Estado, na medida em que os governos pós-impeachment vêm reduzindo drasticamente os recursos com as áreas sociais, dentre elas, a educação básica e superior, comprometendo a implementação do plano e o alcance de suas metas.

As estratégias desse plano não esclarecem como será enfrentado o processo histórico desigual do desenvolvimento social e econômico brasileiro, principalmente, com impacto nas regiões Norte e Nordeste, que representam as áreas com piores níveis de renda e maiores índices de pobreza e de exclusão ao acesso à educação superior. O PNE não explicita como enfrentar as desigualdades regionais e intrarregionais, ou seja, como auxiliar os estados da federação com os piores índices educacionais.

As desigualdades educacionais constituem um grave problema e são intrínsecos à estrutura sócio-econômica-cultural do país. A pobreza expõe sua mais perversa expressão. Entende-se que uma condição fundamental para enfrentar as desigualdades de acesso à educação superior deveria ocorrer pela expansão de vagas pelo setor público e pela contenção do crescimento do setor privado, na medida em que se compreende que a hegemonia do setor privado na oferta de vagas e matrículas não amplia o direito à educação, pelo contrário, afirma a mercantilização da educação.

Vale lembrar que, em 2001, 30,99\% das matrículas eram ofertadas pelo setor público e 69,01\% pelo setor privado. Em 2010, no final do PNE (2001-2010), 25,76\% das matrículas passaram a ser atendidas pelo setor público e $74,24 \%$ pelo setor privado, ou seja, ampliou-se a 
Revista Educação e Políticas em Debate - v. 10, n. 1, p. 379-396, jan./abr. 2021 - ISSN 2238-8346 discrepância em relação à oferta entre as IES públicas e privadas. Em 2014, início do PNE (20142024), o setor público respondia por 25,05\% e o setor privado por 74,95\% (SIEBIGER, 2018).

Dados do Censo da Educação Superior (BRASIL, 2016) indicam que do total de 2.407 IES presentes no país, somente $12,8 \%$ são públicas, e $87,2 \%$ são privadas, sendo $35,9 \%$ na capital e $64,1 \%$ no interior. Contudo, o fato de haver uma maior quantidade percentual de IES em cidades do interior não se traduz diretamente no enfrentamento das desigualdades educacionais. Nas regiões Norte, Nordeste e Sudeste, o quantitativo das IES privadas está acima do patamar de $84 \%$ e nas regiões Sul e Centro-Oeste, atingem mais de $90 \%$. Em relação à quantidade de IES quanto à categoria administrativa, na região Norte, as públicas encontram-se em maior número na capital $(20,8 \%)$, seguidas pela região Centro-Oeste $(11 \%)$, já a região Sul a concentração se dá de forma diferente: $(8,0 \%)$ na capital e $(8,5 \%)$ no interior. Essas regiões apresentam também maior quantidade de IES privadas no interior em relação às demais regiões. Já as regiões Nordeste e Sudeste apresentam as instituições públicas com maior concentração no interior. Portanto, além da maioria expressiva das IES privadas, verifica-se uma heterogeneidade entre as regiões em relação à maior presença das IES públicas em relação à localização na capital e no interior (Tabela 5), fator que pode elevar as desigualdades de acesso.

Tabela 5 - Número de IES capital/interior por localização (capital/interior) segundo a Unidade da Federação e categoria administrativa das IES 2016.

\begin{tabular}{|c|c|c|c|c|c|c|}
\hline $\begin{array}{c}\text { Unidade } \\
\text { Federação/ } \\
\text { Categoria } \\
\text { Administrativa. }\end{array}$ & Total & $\%$ & Capital & $\%$ & Interior & $\%$ \\
\hline Brasil & 2.407 & 100 & 864 & 100 & 1.543 & 100 \\
\hline Pública & 296 & 12,3 & 98 & 11,3 & 198 & 12,8 \\
\hline Privada & 2.111 & 87,7 & 766 & 88,7 & 1.345 & 87,2 \\
\hline Norte & 156 & 100 & 96 & 100 & 60 & 100 \\
\hline Pública & 24 & 15,4 & 20 & 20,8 & 4 & 6,7 \\
\hline Privada & 132 & 84,6 & 76 & 79,2 & 56 & 93,3 \\
\hline Nordeste & 480 & 100 & 237 & 100 & 243 & 100 \\
\hline Pública & 66 & 13,8 & 25 & 10,5 & 41 & 16,9 \\
\hline Privada & 414 & 86,2 & 212 & 89,5 & 202 & 83,1 \\
\hline Sudeste & 1126 & 100 & 304 & 100 & 822 & 100 \\
\hline Pública & 153 & 13,6 & 33 & 10,9 & 120 & 14,6 \\
\hline Privada & 973 & 86,4 & 271 & 89,1 & 702 & 85,4 \\
\hline Sul & 405 & 100 & 112 & 100 & 293 & 100 \\
\hline Pública & 34 & 8,4 & 9 & 8,0 & 25 & 8,5 \\
\hline Privada & 371 & 91,6 & 103 & 92,0 & 268 & 91,5 \\
\hline Centro-Oeste & 240 & 100 & 115 & 100 & 125 & 100 \\
\hline Pública & 19 & 7,9 & 11 & 9,6 & 8 & 6,4 \\
\hline Privada & 221 & 92,1 & 104 & 90,4 & 117 & 93,6 \\
\hline
\end{tabular}

Fonte: Censo da Educação Superior. Sinopse estatística (BRASIL, 2016). Elaboração própria. 
Não há dúvidas de que a redução das desigualdades e assimetrias regionais e intrarregionais passa pelo crescimento de matrículas no setor público. Esse certamente é um grande desafio a ser enfrentado, considerando-se os dados apresentados na Tabela 6, que indica que as regiões Norte e Nordeste possuem um significativo percentual de matrículas localizadas no setor público em relação às demais regiões, sendo 31,0\% e 34,6\% respectivamente. Uma sinalização importante, porém, muito abaixo do patamar das matrículas apresentadas pelo setor privado. A região Sudeste apresenta o maior quantitativo de matrículas no setor privado $(80,7 \%)$, seguida das regiões Sul $(75,7 \%)$ e Centro-Oeste $(76,2 \%)$.

Tabela 6 - Matrículas total dos cursos de graduação (presencial e a distância) segundo Unidade da Federação e categoria administrativa IES 2016.

\begin{tabular}{|c|c|c|}
\hline Unidade Federação/ Categoria Administrativa & Total & $\%$ \\
\hline Brasil & $\mathbf{8 . 0 4 8 . 7 0 1}$ & $\mathbf{1 0 0}$ \\
\hline Pública & 1.990 .078 & 24,7 \\
\hline Privada & 6.058 .623 & 75,3 \\
\hline Norte & $\mathbf{6 5 4 . 9 4 4}$ & $\mathbf{1 0 0}$ \\
\hline Pública & 203.518 & 31,0 \\
\hline Privada & 451.426 & 69,0 \\
\hline Nordeste & $\mathbf{1 . 7 0 3 . 6 7 8}$ & $\mathbf{1 0 0}$ \\
\hline Pública & 588.670 & 34,6 \\
\hline Privada & 1.115 .008 & 65,4 \\
\hline Sudeste & $\mathbf{3 . 6 1 1 . 9 3 9}$ & $\mathbf{1 0 0}$ \\
\hline Pública & 696.118 & 19,3 \\
\hline Privada & 2.915 .821 & 80,7 \\
\hline Sul & $\mathbf{1 . 3 2 6 . 5 3 9}$ & $\mathbf{1 0 0}$ \\
\hline Pública & 322.818 & 24,3 \\
\hline Privada & 1.003 .721 & 75,7 \\
\hline Centro-Oeste & $\mathbf{7 5 1 . 6 0 1}$ & $\mathbf{1 0 0}$ \\
\hline Pública & 178.954 & 23,8 \\
\hline Privada & 572.647 & 76,2 \\
\hline
\end{tabular}

Fonte: Censo da Educação Superior. Sinopse estatística (BRASIL, 2016). Elaboração própria.

Em relação ao número de cursos, a Tabela 7 mostra que as regiões Norte (66\%) e Nordeste $(58,2 \%)$ possuem maior porcentual de cursos das IES públicas no interior, o que constitui em um importante movimento. Já as regiões Sudeste, Sul e Centro-Oeste, tanto nas capitais quanto no interior, a maior quantidade de cursos é ofertada pelo setor privado. Destaca-se a região Norte, que possui uma quantidade aproximada de cursos ofertados tanto no setor público quanto no setor privado e a região Sudeste, apresentando uma quantidade muito significativa de cursos ofertados pelo setor privado (79,2\%). Para além da quantidade de cursos, é necessário ponderar a quantidade de vagas oferecidas, principalmente nas IES públicas, visando à democratização do acesso. 
Revista Educação e Políticas em Debate - v. 10, n. 1, p. 379-396, jan./abr. 2021 - ISSN 2238-8346

Tabela 7 - Número de cursos de graduação presenciais por localização segundo Unidade da Federação e Categoria Administrativa 2016.

\begin{tabular}{|c|c|c|c|c|c|c|}
\hline $\begin{array}{c}\text { Unidade Federação/ } \\
\text { Categoria Administrativa }\end{array}$ & Total & $\%$ & Capital & $\%$ & Interior & $\%$ \\
\hline Brasil & $\mathbf{3 2 . 7 0 4}$ & $\mathbf{1 0 0}$ & $\mathbf{1 2 . 3 0 9}$ & $\mathbf{1 0 0}$ & $\mathbf{2 0 . 3 9 5}$ & $\mathbf{1 0 0}$ \\
\hline Pública & 10.093 & 30,9 & 2.970 & 24,1 & 7.123 & 34,9 \\
\hline Privada & 22.611 & 69,1 & 9.339 & 75,9 & 13.272 & 65,1 \\
\hline Norte & $\mathbf{2 . 4 6 9}$ & $\mathbf{1 0 0}$ & $\mathbf{1 . 3 6 1}$ & $\mathbf{1 0 0}$ & $\mathbf{1 . 1 0 8}$ & $\mathbf{1 0 0}$ \\
\hline Pública & 1.249 & 50,6 & 511 & 37,5 & 738 & 66,6 \\
\hline Privada & 1.220 & 49,4 & 850 & 62,5 & 370 & 33,4 \\
\hline Nordeste & $\mathbf{6 . 3 9 4}$ & $\mathbf{1 0 0}$ & $\mathbf{3 . 1 1 7}$ & $\mathbf{1 0 0}$ & $\mathbf{3 . 2 7 7}$ & $\mathbf{1 0 0}$ \\
\hline Pública & 2.831 & 44,3 & 925 & 29,7 & 1.906 & 58,2 \\
\hline Privada & 3.563 & 55,7 & 2.192 & 70,3 & 1.371 & 41,8 \\
\hline Sudeste & $\mathbf{1 4 . 6 9 7}$ & $\mathbf{1 0 0}$ & $\mathbf{4 . 9 7 8}$ & $\mathbf{1 0 0}$ & $\mathbf{9 . 7 1 9}$ & $\mathbf{1 0 0}$ \\
\hline Pública & 3.050 & 20,8 & 726 & 14,6 & 2.324 & 23,9 \\
\hline Privada & 11.647 & 79,2 & 4.252 & 85,4 & 7.395 & 76,1 \\
\hline Sul & $\mathbf{6 . 2 0 9}$ & $\mathbf{1 0 0}$ & $\mathbf{1 . 3 4 6}$ & $\mathbf{1 0 0}$ & $\mathbf{4 . 8 6 3}$ & $\mathbf{1 0 0}$ \\
\hline Pública & 1.887 & 30,4 & 401 & 29,8 & 1.486 & 30,6 \\
\hline Privada & 4.322 & 69,6 & 945 & 70,2 & 3.377 & 69,4 \\
\hline Centro-Oeste & $\mathbf{2 . 9 3 5}$ & $\mathbf{1 0 0}$ & $\mathbf{1 . 5 0 7}$ & $\mathbf{1 0 0}$ & $\mathbf{1 . 4 2 8}$ & $\mathbf{1 0 0}$ \\
\hline Pública & 1.076 & 36,7 & 407 & 27,0 & 669 & 46,8 \\
\hline Privada & 1.859 & 63,3 & 1.100 & 73,0 & 759 & 53,2 \\
\hline
\end{tabular}

Fonte: Censo da Educação Superior. Sinopse estatística (BRASIL, 2016). Elaboração própria.

A Tabela 8 demonstra a maior dificuldade de acesso às vagas oferecidas pelas instituições, penalizando os cidadãos das regiões Norte $(5,3)$ e Nordeste $(5,1)$ na medida em que a relação candidato/vaga nessas áreas são superiores às demais, bem como a concorrência nas IES públicas. Na região Norte, são $(19,2)$ e na região Nordeste $(18,9)$.

Tabela 8 - Relação candidatos inscritos/vagas oferecidas (deleção para novas vagas) nos cursos de graduação presenciais segundo Unidade da Federação e Categoria Administrativa das IES 2016.

\begin{tabular}{|c|c|}
\hline Unidade Federação/ Categoria Administrativa & Total \\
\hline Brasil & $\mathbf{3 , 5}$ \\
\hline Pública & 14,9 \\
\hline Privada & 1,7 \\
\hline Norte & $\mathbf{5 , 3}$ \\
\hline Pública & 19,2 \\
\hline Privada & 2,0 \\
\hline Nordeste & $\mathbf{5 , 1}$ \\
\hline Pública & 18,9 \\
\hline Privada & 1,7 \\
\hline Sudeste & $\mathbf{2 , 8}$ \\
\hline Pública & 14,5 \\
\hline Privada & 1,6 \\
\hline Sul & $\mathbf{3 , 1}$ \\
\hline Pública & 10,0 \\
\hline Privada & 1,6 \\
\hline Centro-Oeste & $\mathbf{3 , 2}$ \\
\hline Pública & 11,6 \\
\hline Privada & 1,8 \\
\hline
\end{tabular}

Fonte: Censo da Educação Superior. Sinopse estatística (BRASIL, 2016). Elaboração própria. 
Revista Educação e Políticas em Debate - v. 10, n. 1, p. 379-396, jan./abr. 2021 - ISSN 2238-8346

Presume-se que, no PNE (2014-2024), o processo de expansão pela via do setor privado tenderá a persistir, na medida em que o conceito de público foi ressignificado, ao admitir a contabilização dos recursos públicos também para o setor privado. Garcia e Hillesheim (2017) analisam que

a concepção de "público", expresso na lei instituidora do plano, foi ampliada e prevê que a política de educação pode ser implementada por meio de parcerias público-privadas, conforme se denota dos termos do art. $5^{\circ}, \S 4^{\circ}$ da Lei $\mathrm{n}^{\circ}$ 13.005/2014. A despeito disso, essa proposição progressiva de investimentos públicos na política de educação parece que sofrerá com os impactos da desaceleração do crescimento econômico do país, não vislumbrada em sua plena dimensão no momento da elaboração do último PNE em 2014 (GARCIA; HILLESHEIM, 2017, p.139).

Os dados de 2017 reforçam a tendência da dificuldade do cumprimento da meta da expansão de pelo menos $40 \%$ no setor público, visto que perdura a hegemonia do setor privado e a lógica da mercantilização. No período de 2012 a 2016, a participação do setor público na expansão das matrículas nas regiões Norte e Sul diminuiu. Nas demais regiões, cresceram, porém muito abaixo da participação do setor privado. A participação do setor público na expansão do referido período foi de apenas 9,2\% (BRASIL, 2018). Vale dizer que

o crescimento total das matrículas entre 2012 e 2016 foi de 1,01 milhão. Desse total, a rede federal foi a que mais contribuiu para a expansão dentro do segmento público (16,0\%), enquanto as redes estaduais e municipais tiveram diminuição do número de matrículas, contribuindo negativamente ($6,8 \%)$ para o indicador [...] (BRASIL, 2018, p. 215).

Verifica que no mesmo período, o crescimento das matrículas nas IES públicas e privadas por região geográfica foi desigual, além do que o aumento das matrículas em todas as regiões prevaleceu no setor privado. Já a

participação da rede pública na expansão total ficou bem abaixo da meta do PNE de $40 \%$ em todas as grandes regiões. Essa participação foi maior nas regiões Centro-Oeste $(26,8 \%)$ e Sudeste $(23,9 \%)$, seguidas pela região Nordeste $(13,1 \%)$. Entretanto, as regiões Norte $(-17,1 \%)$ e Sul $(-23,8 \%)$ tiveram retração de matrículas entre 2012 e 2016. Enquanto isso, o segmento privado expandiu-se em todas as grandes regiões. Logo, a expansão pública, além de estar muito aquém da meta estabelecida pelo PNE, tem sido desigual em sua distribuição territorial, resultando em retração de matrículas públicas em algumas regiões (BRASIL, 2018, p. 216).

Do total de matrículas na graduação em 2017, somente 24,68\% localizavam no setor público e o setor privado concentrava 75,32\%. Esse cenário compromete o esforço pela redução permanente das desigualdades regionais. Também se constata 
Revista Educação e Políticas em Debate - v. 10, n. 1, p. 379-396, jan./abr. 2021 - ISSN 2238-8346

que o crescimento dos cursos de ensino a distância (EaD) nas IES privadas foi responsável por $43,5 \%$ da expansão total das matrículas entre 2012 e 2016. Em 2012, os cursos de EaD privados contavam com 0,93 milhão de matrículas e passaram a ter 1,37 milhão em 2016, com crescimento de $47,2 \%$ em quatro anos (BRASIL, 2018, p. 215).

A expansão de novas matrículas, principalmente mediante a modalidade Educação a Distância $(\mathrm{EaD})$ pelo setor privado, não indica uma opção satisfatória para as regiões e os estados com índices de maiores desigualdades. Perdura-se a opção pela mercantilização da educação como estratégia para ampliar a cobertura e reduzir, em tese, as desigualdades educacionais. O fortalecimento da expansão de vagas pelo setor público constitui em uma condição fundamental para o enfrentamento das desigualdades regionais.

De acordo com Sampaio (2015), visando alcançar as metas dos PNEs (2001-2010) e (2014-2024) para matricular 30\% e 33\% respectivamente de estudantes de 18 e 24 anos na educação superior, os governos petistas estabeleceram também uma expressiva parceria com o setor privado, na medida em que concederam às IES privadas acesso aos recursos públicos por meio do Fies, além da isenção de impostos e remissão de dívidas por meio do ProUni. Os governos pós-impeachment, além da política de cortes orçamentários e da redução de recursos públicos para os gastos primários, vêm movimentando em direção a continuarem com tais parcerias, como se pode constatar na continuidade dos financiamentos via Fies e ProUni.

Outra questão comprometedora que atinge as metas de expansão para o PNE (20142024) remete ao Novo Regime Fiscal aprovado pelo governo de Michel Temer (20162018 ), em dezembro de 2016.

A Emenda Constitucional 95/2016 (EC 95) instituiu uma regra para as despesas primárias do Governo Federal com duração de 20 anos e possibilidade de revisão - restrita ao índice de correção - apenas após 10 anos. Nessa regra, o gasto primário do governo federal fica limitado por um teto definido pelo valor executado em 2017, e reajustado, a cada ano, pela inflação acumulada, em 12 meses medida pelo Índice Nacional de Preços ao Consumidor Amplo (IPCA). Em síntese, o novo regime fiscal institui uma austeridade permanente. $\mathrm{O}$ não crescimento real das despesas totais do Governo Federal resultará em uma redução do gasto público relativamente ao PIB e per capita (devido ao crescimento da população ao longo dos anos). [...] o gasto com saúde e educação deve se ater ao novo mínimo que, desvinculado das receitas de impostos, deve cair de 2,41\% do PIB em 2017 para 1,93\% do PIB em 2026 e 1,5\% do PIB em 2036 (DWECK; OLIVEIRA; ROSSI, 2018, p. 24-25).

A redução da participação do Estado na economia e na formulação e implementação de políticas públicas, particularmente as sociais, diminui expressivamente os recursos públicos na garantia dos direitos sociais, precarizando os serviços sociais e transferindo a responsabilidade para o mercado no fornecimento de bens sociais. O governo de Jair 
Revista Educação e Políticas em Debate - v. 10, n. 1, p. 379-396, jan./abr. 2021 - ISSN 2238-8346 Bolsonaro (2019-2022) afirmou que não irá modificar a Emenda. Nesse sentido, a EC 95/2016 promoverá a regressão de grande parte das políticas de expansão e de democratização do acesso à educação superior (AMARAL, 2017).

\section{Considerações finais}

A luta dos setores organizados da sociedade civil em defesa da democratização do acesso à educação superior para toda população brasileira e do PNE como uma política de Estado sofreu um duro golpe com a promulgação da PEC 95/2016, pelo governo Michel Temer (2016-2018), que estabeleceu um regime fiscal de congelamento dos gastos primários por 20 anos e com o governo de Jair Bolsonaro (2019-2022), que vem contingenciando financiamento público para educação básica e superior.

Além desses fatores, as políticas e os programas de expansão das matrículas do PNE 2014-2024, que visam atingir as metas de 50\% para TBM e 33\% da TLM, necessitariam articular ações que auxiliassem as regiões e os estados da federação com piores índices a aproximem das regiões e dos estados com posições mais vantajosas, minimizando as desigualdades e democratizando o acesso à educação superior.

Os dados educacionais devem ser analisados de forma abrangente mediante o cruzamento de diversas variáveis, compreendendo as especificidades das localidades e das regiões para que o acesso e a permanência na educação superior sejam um direito de todo cidadão brasileiro.

Quanto à TBM, nos estados da região Nordeste, constata-se que estão todas abaixo da média nacional. A região Norte apresenta significativas disparidades - estados com taxas mais altas que a média nacional e outros muito aquém da média. As regiões Sul e Sudeste demonstram maior homogeneidade intrarregional na oferta de matrículas. Na região CentroOeste, a assimetria intrarregional ocorre, principalmente, devido à elevada oferta de matrículas no Distrito Federal. Seus índices ultrapassaram a meta da TBM $(50 \%)$ e praticamente já alcançou a TLM (33\%). De outro modo, destaca-se o estado de Goiás que apresenta um índice da TBM significativamente inferior ao estado do Mato Grosso.

Na medida em que a oferta das matrículas da graduação no PNE (2014-2024) continua hegemonicamente a ser ofertada pelas IES privadas e com os cortes anunciados para setor público, a meta almejada de expansão de pelo menos 40\% nas IES públicas no total de matrículas fica muito comprometida, bem como a inclusão e a democra tização do acesso, principalmente, para as regiões socioeconômicas mais pobres que ficam cada vez mais distantes de conquistar o direito do acesso à educação pública e de qualidade socialmente referenciada. 
Revista Educação e Políticas em Debate - v. 10, n. 1, p. 379-396, jan./abr. 2021 - ISSN 2238-8346

Nesse sentido, as políticas em curso para esse nível de educação continuam a atender aos interesses mercantis, bem como a expansão de vagas na educação superior continua ocorrendo de maneira assimétrica, perpetuando, até o momento, a exclusão, principalmente, de grande parte da população das regiões Norte e Nordeste. Por isso, torna-se necessário a criação de novas políticas que possibilitem a ampliação do acesso e da permanência, visando alcançar uma efetiva democratização ao enfrentar as expressivas desigualdades regionais.

\section{Referências}

AMARAL, N. C. Com a PEC 241/55 (EC 95) haverá prioridade para cumprir as metas do PNE (2014-2024)? Rev. Bras. Educ. [online]. 2017, vol.22, n.71. ISSN 1809-449X. DOI: http://dx.doi.org/10.1590/s 1413-24782017227145.

BRASIL. Lei n $n^{\circ}$ 13.005, de 25 de junho de 2014. Aprova o Plano Nacional de Educação-PNE e dá outras providências. Disponível em: http://www.planalto.gov.br/ccivil_03/_Ato20112014/2014/Lei/L13005.htm. Acesso em: 10 jan. 2019.

BRASIL. Constituição da República Federativa do Brasil de 1988. Disponível em: https://www2.senado.leg.br/bdsf/bitstream/handle/id/518231/CF88_Livro_EC91_2016.pdf. Acesso em: 24 ago. 2019.

BRASIL. Instituto Nacional de Estudos e Pesquisas Educacionais Anísio Teixeira (INEP). Relatório do $1^{\circ}$ ciclo de monitoramento das metas do PNE: biênio 2014-2016. Brasília, DF: Inep, 2016 .590p.

BRASIL. Instituto Nacional de Estudos e Pesquisas Educacionais Anísio Teixeira (INEP). Sinopse Estatística da Educação Superior, 2016. Disponível em: http://inep.gov.br/web/guest/sinopsesestatisticas-da-educacao-superior. Acesso em: 20 maio 2019.

BRASIL. Instituto Nacional de Estudos e Pesquisas Educacionais Anísio Teixeira (INEP). Relatório do $2^{\circ}$ Ciclo de Monitoramento das Metas do Plano Nacional de Educação-2018. Brasília, DF: Inep, 2018. 460 p.

DIDONET, Vital (apresentação). Plano Nacional de Educação. Brasília: Editora Plano, 2000.

DWECK, E.; OLIVEIRA, A. L. M. de, ROSSI, P. (Coord.). Austeridade e retrocesso: impactos sociais da política fiscal no Brasil. São Paulo: Brasil Debate e Fundação Friedrich Ebert, agosto de 2018. Disponível em: http://library.fes.de/pdffiles/bueros/brasilien/14632.pdf. Acesso em: 25 ago. 2019.

FAVERI, D. B. de; PETTERINI, F. C.; BARBOSA, M. P. Uma avaliação do impacto da política de expansão dos institutos federais nas economias dos municípios brasileiros. Planejamento $e$ Políticas Públicas, n. 50, jan./jun. 2018. Disponível em: http://www.ipea.gov.br/ppp/index.php/PPP/article/view/742/464. Acesso em: 25 ago. 2019. 
Revista Educação e Políticas em Debate - v. 10, n. 1, p. 379-396, jan./abr. 2021 - ISSN 2238-8346

GARCIA, A. V.; HILLESHEIM, J. Pobreza e desigualdades educacionais: uma análise com base nos Planos Nacionais de Educação e nos Planos Plurianuais Federais. Educ. Rev., Curitiba, Brasil, Edição Especial n. 2, p. 131-147, set. 2017. DOI:

http://dx.doi.org/10.1590/0104-4060.51386.

MAUÉS, O. A educação superior no Plano Nacional de Educação, 2011-2020: A proposta do executivo. $34^{\circ}$ Encontro ANPED, 2011. Disponível em: http://flacso.org.br/?publication=aeducacao-superior-no-plano-nacional-de-educacao-2011-2020-a-proposta-do-executivo.

Acesso em: 04 jan. 2018.

MINTO, L. W. Educação superior no PNE (2014-2024): apontamentos sobre as relações público-privadas. Rev. Bras. Educ. [online]. 2018, vol.23, e230011. ISSN 1809-449X. http://dx.doi.org/10.1590/s1413-24782018230011.

MONT'ALVÃO, A. Diferenciação institucional e desigualdades no ensino superior. Rev. bras. Ci. Soc. [online]. 2015, vol.30, n.88, pp.129-143. ISSN 1806-9053. DOI : http://dx.doi.org/10.17666/3088129-143/2015.

RISTOFF, D. Vinte e um anos de Educação superior Expansão e Democratização. Cadernos do GEA, n.3 (jan./jun. 2013). Rio de Janeiro: FLACSO, GEA; UERJ, LPP, 2013.

SAMPAIO, H. Novas dinâmicas do ensino superior no Brasil: o público e o privado. Opinião N. 23. Rio de Janeiro: Flacso Brasil/Grupo Estratégico de análise da educação superior no Brasil. Nov. 2015.

SIEBIGER, R. H. Desafios no atendimento das metas do plano nacional de educação pelo segmento público: elevação das taxas de matrícula na educação superior. Atos de Pesquisa em Educação. Blumenau, v. 13, n.3, p.503-524, set./dez. 2018. DOI:

http://dx.doi.org/10.7867/1809-0354.2018v13n3p503-524

VARGAS, H. M. Interiorização da educação superior pública no Brasil: pontos de atenção, ajustes e autonomia universitária. Revista de Estudios Brasileños, v. 3, n. 5, 2015. 